\title{
sciendo
}

\section{THE EFFECT OF EMULSIFIER ON GROWTH PERFORMANCE AND FAT DIGESTIBILITY IN TURKEYS*}

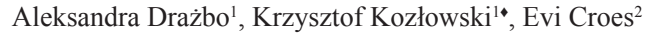 \\ ${ }^{1}$ Department of Poultry Science, University of Warmia and Mazury, \\ Oczapowskiego 5, 10-718 Olsztyn, Poland \\ ${ }^{2}$ Nukamel B.V., Industriekade 32-34, 6001 SE Weert, The Netherlands \\ •Corresponding author: kristof@uwm.edu.pl
}

\begin{abstract}
The present study investigated the effect of an emulsifier with very high hydrophilic-to-lipophilic balance (HLB) value (18) on growth performance and fat digestibility in turkeys. A total of 1120 day-old female Hybrid Converter turkeys were randomly divided into four treatment groups with 7 replicates (pens) of 40 birds each. Control group (T1) turkeys were fed a basal diet (BD), while turkeys from experimental groups received different levels of the commercial emulsifier $\mathrm{VE}$ added to diets with standard or reduced metabolizable energy (ME) content: T2 - BD + 500 ppm of VE; $\mathrm{T} 3$ - BD + $500 \mathrm{ppm}$ of $\mathrm{VE}$ until 8 weeks of age, and $250 \mathrm{ppm}$ from 9 to 16 weeks; T4 - BD - 3\% ME +500 ppm of VE until 8 weeks of age, and 250 ppm from 9 to 16 weeks. Regardless of its dietary inclusion level $(500 \mathrm{~g} /$ ton and $500 / 250 \mathrm{~g} /$ ton feed $)$, the emulsifier positively influenced the body weights (BW) and body weight gains (BWG) of birds. On days 56 and 112, significant differences in the values of these parameters were noted between the control treatment (T1) vs. groups T2 and T3. Emulsifier addition even contributed to an increase in the BWG and BW of birds receiving diets with 3\% lower ME content, as compared with turkeys fed control diets. This shows that the emulsifier more than compensated the reduction in ME in T4. The turkeys from group T3 were characterized by significantly higher feed efficiency than $\mathrm{T} 1$ and $\mathrm{T} 4$ birds. The highest fat digestibility was noted in turkeys fed diets with a standard ME level and emulsifier addition (T2 and T3). In conclusion, the use of dietary emulsifier positively influences the growth performance of turkeys, and improves fat digestibility.
\end{abstract}

Key words: turkeys, emulsifier, growth performance, fat digestibility

It has become common practice to add fat and oil to commercial turkey diets in order to meet the high energy requirements of the birds. The addition of fat sources increases dietary energy levels. Other benefits involve improved feed efficiency, increased growth rates of birds, decreased dustiness of feeds, lower heat increment

*This work was supported by Nukamel B.V., Weert, The Netherlands. 
during heat stress, and feed palatability. On the other hand, excess fat in the young animal's diet leads to improper digestion, lower feed intake (FI) and lower body weight gains (BWG) resulting in economic losses and posing a threat to the birds' life (Abbas et al., 2016). Fat is mainly composed of triglycerides and, although fats are not water-soluble, its digestion takes place in an aqueous environment of the gastrointestinal tract, where it is hydrolyzed by lipase into fatty acids and mono- and diglycerides (Zaefarian et al., 2015). It should be noted that fat digestibility varies depending on fat type, feed composition and bird's age, because young turkeys have limited physiological capacity for fat absorption (Nir et al., 1993; Lima et al., 2003; Guerreiro Neto et al., 2011). Fat digestion and absorption is a complex process that requires bile salts (natural emulsifiers), pancreatic lipase and colipase and, according to several studies, intestinal fatty acid-binding proteins (Sell et al., 1986). An improvement in fat utilization with age is largely a function of increased bile production and enhanced intestinal lipase activity as the poult matures. Bile salt secretion in particular was found to be the first limiting step in lipid digestion (Krogdahl, 1985). Because young turkeys are slaughtered before maturity, bile secretion is not sufficient, therefore the addition of emulsifiers to high-fat diets may improve fat utilization (Abd El Rauof, 2007). Emulsifiers act synergistically with natural bile salts in the animal's gut. The mode of action of emulsifiers is to increase the active surface of fats, allowing the action of lipases that hydrolyze triglyceride molecules into fatty acids and monoglycerides, and to favor the formation of micelles consisting of lipolysis products. Micelle formation is an essential step for lipid absorption, as it creates a diffusion gradient that promotes absorption (Guerreiro Neto et al., 2011). It was found that exogenous supplementation of emulsifiers may enhance fat utilization and improve the growth performance of broilers (Polin, 1980; Roy et al., 2010) and pigs (Jones et al., 1992; Dierick and Decuypere, 2004), whereas the efficacy of emulsifiers in turkey nutrition, including their effect on growth performance and fat digestibility, remains insufficiently investigated.

The ability of an emulsifier to be active as a biosurfactant in the watery environment of the gut and aid in fat digestion highly depends on the size and strength of the hydrophilic or polar portion of the molecule - a quality which makes the emulsifier more soluble in the aqueous medium of the small intestine and brings it into contact with a greater number of fat molecules and facilitates their digestion and absorption (Roy et al., 2008). The emulsifier used in the current experiment has been classified as glycerol polyethylene glycol ricinoleate (GPR). It has high HLB (hydrophilic-tolipophilic balance) values (18), which is very important from a nutritional point of view. As the digestive tract is a watery environment, an emulsifier with high HLB values and thus very hydrophilic in nature is needed to form an oil-in-water emulsion. According to Roy et al. (2010), dietary addition of GPR improves fat utilization in chickens. Kaczmarek et al. (2015) demonstrated that GPR had a positive effect on the digestion of animal fat/rapeseed oil blends.

In view of the fact that there is a general scarcity of studies investigating the efficacy of emulsifiers in turkey diets, the objective of this experiment was to determine the effect of emulsifier on growth performance and fat digestibility in turkeys. 


\section{Material and methods}

\section{Animals and treatment}

The experiment was carried out in a poultry house in Bałdy, owned by the University of Warmia and Mazury (UWM) in Olsztyn, Poland. All procedures used in this experiment were approved by the Animal Ethics Committee.

Table 1. Composition and nutritional value of basal diets fed to turkeys in groups T1, T2 and T3 in successive feeding phases $(\%)$

\begin{tabular}{lccccc}
\hline \multicolumn{1}{c}{ Compounds } & P-1 (1-4 wk) & P-2 (5-8 wk) & P-3 (9-12 wk) & P-4 (13-16 wk) \\
\hline Wheat & 45.04 & 47.57 & 55.89 & 64.57 \\
Soybean meal & 39.34 & 38.84 & 29.41 & 20.86 \\
Rapeseed meal & 3.00 & 4.00 & 5.00 & 5.00 \\
Potato protein & 4.00 & - & - & - \\
Soybean oil & 2.30 & 2.56 & 1.90 & 1.53 \\
Animal fat & 1.15 & 2.55 & 3.79 & 4.62 \\
NaHCO & 0.10 & 0.10 & 0.10 & 0.10 \\
Salt & 0.23 & 0.21 & 0.21 & 0.17 \\
Limestone & 1.83 & 1.51 & 1.51 & 1.46 \\
MCP & 1.91 & 1.42 & 0.98 & 0.67 \\
Choline chloride & 0.07 & 0.07 & 0.07 & 0.07 \\
DL-methionine & 0.31 & 0.34 & 0.32 & 0.26 \\
Lysine & 0.34 & 0.44 & 0.39 & 0.35 \\
Threonine & 0.12 & 0.14 & 0.18 & 0.10 \\
Premix ${ }^{1}$ & 0.25 & 0.25 & 0.25 & 0.25 \\
& Nutritional value (g/kg) & & \\
ME (kcal/kg) & 2802 & 2900 & 3000 & 3100 \\
Crude protein & 279.95 & 255.00 & 225.00 & 195.00 \\
Methionine & 7.21 & 6.96 & 6.39 & 5.44 \\
Met+Cys & 11.80 & 11.30 & 10.40 & 9.10 \\
Lysine & 17.50 & 16.20 & 13.70 & 11.40 \\
Threonine & 11.60 & 10.30 & 9.50 & 7.50 \\
Arginine & 17.16 & 15.88 & 13.56 & 11.33 \\
Calcium & 12.00 & 10.00 & 9.00 & 8.00 \\
Available phosphorus & 6.00 & 5.00 & 4.00 & 3.30 \\
\hline
\end{tabular}

${ }^{1}$ Premix - see Table 3.

A total of 1120 day-old female Hybrid Converter turkeys, supplied by a commercial hatchery, were randomly divided into four treatment groups with 7 replicates of 40 birds each, and were kept in floor pens $\left(0.25 \mathrm{~m}^{2}\right.$ for 1 bird $)$. The house was provided with artificial programmable lights and climate, automated electric heating and forced ventilation. The heating program was consistent with the recommendations of Hybrid Turkeys (2016). Wood shavings were used as bedding material, and the litter was replenished as necessary. Drinking water was supplied ad libitum by a self-filling system. Each pen was equipped with a feeder manually filled with bags on a daily basis. The lighting program was as follows: full lighting with an intensity 
of $100 \mathrm{~lx}$ for the first 36 hours followed by 16L:8D until the end of the rearing period; from 3 days of age, light intensity was decreased to reach $5 \mathrm{~lx}$ on day 7, and then it was increased to $15 \mathrm{~lx}$ at 35 days of age.

Table 2. Composition and nutritional value of basal diets fed to turkeys in group T4 in successive feeding phases $(\%)$

\begin{tabular}{lccccc}
\hline \multicolumn{1}{c}{ Compounds } & P-1 (1-4 wk) & P-2 $(5-8 \mathrm{wk})$ & P-3 (9-12 wk) & P-4 (13-16 wk) \\
\hline Wheat & 47.17 & 49.80 & 58.22 & 67.00 \\
Soybean meal & 38.78 & 38.25 & 28.78 & 20.21 \\
Rapeseed meal & 3.00 & 4.00 & 5.00 & 5.00 \\
Potato protein & 4.00 & - & - & - \\
Soybean oil & 1.25 & 1.74 & 1.33 & 1.09 \\
Animal fat & 0.63 & 1.73 & 2.65 & 3.28 \\
NaHCO & 0.10 & 0.10 & 0.10 & 0.10 \\
Salt & 0.23 & 0.21 & 0.21 & 0.17 \\
Limestone & 1.84 & 1.52 & 1.52 & 1.47 \\
MCP & 1.89 & 1.41 & 0.96 & 0.66 \\
Choline chloride & 0.07 & 0.07 & 0.07 & 0.07 \\
DL-methionine & 0.31 & 0.34 & 0.32 & 0.26 \\
Lysine & 0.35 & 0.45 & 0.40 & 0.36 \\
Threonine & 0.13 & 0.14 & 0.18 & 0.10 \\
Premix ${ }^{1}$ & 0.25 & 0.25 & 0.25 & 0.25 \\
& Nutritional value (g/kg) & & \\
ME (kcal/kg) & 2718 & 2813 & 2910 & 3007 \\
Crude protein & 280.00 & 255.00 & 225.00 & 195.00 \\
Methionine & 7.19 & 6.93 & 6.37 & 5.41 \\
Met+Cys & 11.80 & 11.30 & 10.40 & 9.10 \\
Lysine & 17.50 & 16.20 & 13.70 & 11.40 \\
Threonine & 11.60 & 10.30 & 9.50 & 7.50 \\
Arginine & 17.11 & 15.82 & 13.49 & 11.26 \\
Calcium & 12.00 & 10.00 & 9.00 & 8.00 \\
Available phosphorus & 6.00 & 5.00 & 4.00 & 3.30 \\
\hline
\end{tabular}

${ }^{1}$ Premix - see Table 3.

The composition and nutritional value of basal diets for four feeding phases (P1: 1-4, P2: 5-8, P3: 9-12, P4: 13-16 weeks) are shown in Tables 1 and 2. Diets, offered in crumbled/pelleted form, were formulated to meet the nutrient and energy requirements of turkeys (Hybrid Turkeys, 2016). All diets contained phytase and xylanase at similar levels (so T1 till T4). Control group (T1) turkeys were fed a basal diet (BD) based on wheat and soybean meal, while turkeys from experimental groups received different levels of the commercial emulsifier Volamel Extra (VE; Nukamel, The Netherlands) added to diets with standard (BD) or reduced metabolizable energy (ME) content: T2 - BD +500 ppm of VE; T3 - BD + 500 ppm of VE until 8 weeks of age, and $250 \mathrm{ppm}$ from 9 to 16 weeks; T4 - BD - 3\% ME + 500 ppm of VE until 8 weeks of age, and 250 ppm from 9 to 16 weeks. Basic composition analyses were performed, using standard procedures (Naumann and Bassler, 2004). All diets were 
assayed for crude protein (VDLUFA III 4.1.1 modified according to macro-N determination (vario Max CN)), crude fiber (VDLUFA III 6.1.4), crude fat (VDLUFA III 5.1.1), dry matter (DM; VDLUFA III 3.1) and ash (VDLUFA III 8.1) content. Titanium dioxide $(0.3 \%)$ was included in diet P3 as an inert marker. The concentration of $\mathrm{TiO}_{2}$ in feed and digesta was measured using the method described by Short et al. (1996). Chemical analyses of feed were performed at UWM.

Table 3. Composition of $1 \mathrm{~kg}$ of premix (vitamins and trace minerals)

\begin{tabular}{l|c|c|c}
\hline \multicolumn{1}{c}{ Compounds } & Units & Diets P1 and P2 & Diets P3 and P4 \\
\hline Vitamin $\mathrm{A}$ & $\mathrm{IU}$ & 5.000 .000 & 3.840 .000 \\
Vitamin $\mathrm{D}_{3}$ & $\mathrm{IU}$ & 1.330 .000 & 1.920 .000 \\
${\text { Vitamin } \mathrm{D}_{3}(\mathrm{HyD})}^{\text {Vitamin E }}$ & $\mathrm{IU}$ & 670.000 & - \\
Vitamin $\mathrm{K}_{3}$ & $\mathrm{mg}$ & 40.000 & 24.000 \\
Vitamin $\mathrm{B}_{1}$ & $\mathrm{mg}$ & 1.600 & 1.200 \\
Vitamin $\mathrm{B}_{2}$ & $\mathrm{mg}$ & 1.800 & 800 \\
Vitamin $\mathrm{B}_{6}$ & $\mathrm{mg}$ & 6.000 & 4.800 \\
Vitamin $\mathrm{B}_{12}$ & $\mathrm{mg}$ & 2.000 & 2.000 \\
Folic acid & $\mathrm{mg}$ & 16 & 10 \\
Pantothenic acid & $\mathrm{mg}$ & 1.400 & 1.000 \\
Nicotinic acid & $\mathrm{mg}$ & 11.200 & 9.200 \\
Biotin & $\mathrm{mg}$ & 44.000 & 34.000 \\
Manganese & $\mathrm{mg}$ & 150 & 150 \\
Zinc & $\mathrm{mg}$ & 64.000 & 48.000 \\
Iron & $\mathrm{mg}$ & 64.000 & 48.000 \\
Copper & $\mathrm{mg}$ & 32.000 & 16.000 \\
Iodine & $\mathrm{mg}$ & 10.000 & 10.000 \\
Selenium & $\mathrm{mg}$ & 1.000 & 800 \\
\hline
\end{tabular}

\section{Production parameters and fat digestibility}

The body weights (BW) of turkeys, FI and mortality rates were determined throughout the experiment. The BW of birds in each pen were recorded at 28, 56, 84 and 112 days of age (on a pen basis). The BWG of birds and feed conversion ratio (FCR) were calculated for each group. During the final two days of the experiment (d 83 and d 84), morning and afternoon, clean excreta (free from feathers, litter and feed) were collected from plastic liners placed in the excreta collection trays $(0.6 \times 0.4 \mathrm{~m})$ underneath each pen of birds, and DM content and fat digestibility were determined. Fat digestibility was determined using the titanium marker content of diets and feces. For this measurement, 7 samples were taken from each treatment group. Fat digestibility was calculated using the following equation (Hill et al., 1960): fat digestibility $(\%)=\left\{1-\left[\left(\mathrm{TiO}_{2 \% \text { diet }} / \mathrm{TiO}_{2 \% \text { feces }}\right) \times\left(\right.\right.\right.$ fat $_{\% \text { feces }} /$ fat $\left.\left.\left._{\% \text { diet }}\right)\right]\right\} \times 100$.

\section{Statistical analysis}

The results of the experiment were verified by one-way analysis of variance (ANOVA) using the Statistica for Windows Operating System (StatSoft Inc., 2011). Mortality data were subjected to arcsin transformation prior to the analysis. The sig- 
nificance of differences between groups was determined by the $F$-test. The differences were considered significant at $\mathrm{P} \leq 0.05$, and $0.05<\mathrm{P}<0.10$ values were considered as a near-significant trend.

\section{Results}

Throughout the experiment (1-112 days), mortality rates ranged from 1.07 to $1.79 \%$, and no significant differences were found between groups (Table 4 ). The addition of emulsifier positively influenced the BWG and BW of birds (from 28 days of age until the end of the experiment). On day 28, turkeys from groups $\mathrm{T} 2$ and $\mathrm{T} 3$ were numerically heavier than control group birds $(\mathrm{T} 1)$, and tended $(\mathrm{P}=0.056)$ to be heavier than birds receiving diets with reduced ME content (T4). On day 56, significant differences in the values of these parameters were noted between the control treatment (T1) vs. groups T2 and T3 (5.50 and 5.58\%, respectively). Group T4 birds were also significantly (4.48\%) heavier than control group birds (T1). During the entire experimental period, the addition of the emulsifier at both inclusion levels $(500$ $\mathrm{g} /$ ton and 500/250 $\mathrm{g} /$ ton feed) resulted in significant differences $(3.08$ and $4.16 \%$ in groups T2 and T3, respectively) in the BW and BWG of birds. Tested emulsifier caused an increase in the BW $(2.43 \%)$ and BWG of birds receiving diets with $3 \%$ lower ME content, as compared with turkeys fed control diets.

Until day 84, no differences were noted in daily FI between treatments. Between 85 and 112 days, group T4 birds were characterized by significantly higher FI compared with group $\mathrm{T} 1$ birds $(\mathrm{P}=0.044)$. No differences were found in FI between groups throughout the experiment. From 1 to 28 days of age, significant differences were observed in FCR between treatments. Turkeys from groups T1-T3 were characterized by significantly higher feed efficiency (2.02 to $3.03 \%$ ) than group T4 birds. Significant differences were also noted in the period from 85 to 112 days, when feed efficiency was higher in group T3 birds than in turkeys from groups T1 and T4 (8.04 and $7.35 \%$, respectively). The same results were obtained for the entire experiment where the differences between group T3 vs. treatments T1 and T4 reached 3.23 and $3.70 \%$, respectively.

Table 4. Growth performance of turkeys fed diets supplemented with different rates of emulsifier

\begin{tabular}{|c|c|c|c|c|c|c|}
\hline \multirow{2}{*}{ Item, days } & \multicolumn{4}{|c|}{ Treatment } & \multirow{2}{*}{ SEM } & \multirow{2}{*}{$\mathrm{P}$} \\
\hline & $\mathrm{T} 1$ & $\mathrm{~T} 2$ & $\mathrm{~T} 3$ & $\mathrm{~T} 4$ & & \\
\hline 1 & 2 & 3 & 4 & 5 & 6 & 7 \\
\hline \multicolumn{7}{|l|}{ BW (kg) } \\
\hline 1 & 0.054 & 0.054 & 0.054 & 0.054 & 0.000 & 0.293 \\
\hline 28 & 0.993 xy & $1.006 \mathrm{x}$ & $1.011 \mathrm{x}$ & $0.966 \mathrm{y}$ & 0.007 & 0.056 \\
\hline 56 & $3.638 \mathrm{~b}$ & $3.838 \mathrm{a}$ & $3.841 \mathrm{a}$ & $3.801 \mathrm{a}$ & 0.025 & 0.003 \\
\hline 84 & 7.545 & 7.728 & 7.592 & 7.623 & 0.033 & 0.242 \\
\hline 112 & $10.877 \mathrm{~b}$ & $11.212 \mathrm{a}$ & $11.330 \mathrm{a}$ & $11.141 \mathrm{ab}$ & 0.060 & 0.041 \\
\hline
\end{tabular}


Table 4 - contd.

\begin{tabular}{|c|c|c|c|c|c|c|}
\hline 1 & 2 & 3 & 4 & 5 & 6 & 7 \\
\hline \multicolumn{7}{|l|}{ BWG (g/day) } \\
\hline $1-28$ & 33.5 xy & $34.0 \mathrm{x}$ & $34.2 \times$ & $32.6 \mathrm{y}$ & 0.236 & 0.062 \\
\hline $29-56$ & $94.5 \mathrm{~b}$ & $101.2 \mathrm{a}$ & $101.1 \mathrm{a}$ & $101.2 \mathrm{a}$ & 0.813 & 0.001 \\
\hline $57-84$ & 139.6 & 138.9 & 134.0 & 136.5 & 0.987 & 0.171 \\
\hline $85-112$ & $123.4 \mathrm{~b}$ & $129.0 \mathrm{ab}$ & $138.5 \mathrm{a}$ & $130.3 \mathrm{ab}$ & 1.915 & 0.037 \\
\hline $1-112$ & $97.5 \mathrm{~b}$ & $100.5 \mathrm{a}$ & $101.6 \mathrm{a}$ & $99.9 \mathrm{ab}$ & 0.540 & 0.041 \\
\hline \multicolumn{7}{|l|}{ FI (g/day) } \\
\hline $1-28$ & 51.6 & 52.0 & 53.2 & 51.1 & 0.362 & 0.229 \\
\hline $29-56$ & 191.5 & 200.4 & 204.6 & 202.5 & 2.168 & 0.148 \\
\hline $57-84$ & $331.4 \mathrm{x}$ & $327.3 \mathrm{xy}$ & $316.3 \mathrm{y}$ & $330.9 x$ & 0.348 & 0.072 \\
\hline $85-112$ & $443.2 \mathrm{~b}$ & $457.3 \mathrm{ab}$ & $455.4 \mathrm{ab}$ & $464.1 \mathrm{a}$ & 2.731 & 0.044 \\
\hline $1-112$ & 255.0 & 260.0 & 261.8 & 263.4 & 1.376 & 0.146 \\
\hline \multicolumn{7}{|l|}{ FCR $(\mathrm{kg} / \mathrm{kg})$} \\
\hline $1-28$ & $1.538 \mathrm{a}$ & $1.543 \mathrm{a}$ & $1.554 \mathrm{a}$ & $1.586 \mathrm{~b}$ & 0.006 & 0.016 \\
\hline $29-56$ & 2.029 & 1.981 & 2.014 & 2.001 & 0.020 & 0.858 \\
\hline $57-84$ & 2.368 & 2.349 & 2.361 & 2.411 & 0.016 & 0.555 \\
\hline $85-112$ & $3.605 b$ & $3.517 \mathrm{ab}$ & $3.315 \mathrm{a}$ & $3.578 \mathrm{~b}$ & 0.042 & 0.048 \\
\hline $1-112$ & $2.571 \mathrm{~b}$ & $2.535 \mathrm{ab}$ & $2.488 \mathrm{a}$ & $2.583 \mathrm{~b}$ & 0.013 & 0.032 \\
\hline Mortality (\%) & 1.07 & 1.79 & 1.07 & 1.79 & 0.001 & 0.894 \\
\hline
\end{tabular}

BW - body weight, BWG - body weight gain, FI - feed intake, FCR - feed conversion ratio; a, b - values in rows denoted by different letters differ significantly $(\mathrm{P}<0.05), \mathrm{x}, \mathrm{y}-$ near significant trend $(0.05<\mathrm{P}<0.10)$.

Table 5 presents the effect of emulsifier on fecal DM content and fat digestibility coefficients. No differences were found in fecal DM content between treatments. Fat digestibility was significantly higher in turkeys from groups T2 and T3 than in control group birds (T1). Turkeys fed diets with reduced ME content, supplemented with emulsifier (T4), were characterized by the same fat digestibility as control group birds (T1).

Table 5. Fecal dry matter content and fat digestibility coefficients (\%)

\begin{tabular}{|c|c|c|c|c|c|c|}
\hline & \multicolumn{4}{|c|}{ Treatment } & \multirow{2}{*}{ SEM } & \multirow{2}{*}{$\mathrm{P}$} \\
\hline & $\mathrm{T} 1$ & $\mathrm{~T} 2$ & $\mathrm{~T} 3$ & $\mathrm{~T} 4$ & & \\
\hline Fecal DM content & 18.66 & 18.16 & 18.14 & 18.81 & 0.256 & 0.740 \\
\hline Fat digestibility & $83.60 \mathrm{~b}$ & $86.07 \mathrm{a}$ & $86.14 \mathrm{a}$ & $84.06 \mathrm{ab}$ & 0.394 & 0.026 \\
\hline
\end{tabular}

$\mathrm{DM}$ - dry matter; $\mathrm{a}, \mathrm{b}$ - values in rows denoted by different letters differ significantly $(\mathrm{P}<0.05)$.

\section{Discussion}

The tested emulsifier positively influenced the BWG and final BW of turkeys. A tendency towards higher values of the above parameters was observed from 28 days of age, and significant differences between groups were observed from 56 days. Literature provides scant information on the use of emulsifiers in turkey nutrition. 
However, the results of this study are in accordance with experiments in broiler chickens performed by Roy et al. (2010), Maertens et al. (2013) and Abbas et al. (2016), in which the addition of an emulsifier improved the BWG of birds from the second feeding phase onwards. Kaczmarek et al. (2015) reported that a supplemental emulsifier improved fat digestibility in 14-day-old broilers, but when FI was taken into account, dietary fat utilization was found to increase by only $1.2 \mathrm{~g}$ per bird over the entire 14-day period. This explains why no improvement was noted in the growth performance of birds in the starter phase.

However, Wang et al. (2016) demonstrated that the supplementation of emulsifier in broiler diets is more efficient in the starter phase, because lipase secretion and activity in young chicks are insufficient and reach a peak between days 40 and 56 of age. Research of Zhang et al. (2011) also showed that the addition of lysophosphatidylcholine increased BWG and tended to reduce FCR of broiler chickens in the starter period. These contradictory results could be linked to the low level of lipase production in young birds. According to Krogdahl and Sell (1989), lipase activity increases in turkeys during the first eight weeks of their life, although the pancreas reaches adult size at 14 days post hatch. Moreover, they found that the development of the intestinal lipase activity depends on dietary fat level and composition. As Meng et al. (2004) found no effect of lipase addition on chicken performance and nutrient utilization they suggested that lipase secretion in young birds may not be as inadequate as expected when estimated based on FI (Sklan, 2001). It is well documented in the literature that lipid digestion/absorption improves with age and the magnitude of the improvement is greater for lipid sources with high levels of saturated versus unsaturated fatty acids (Whitehead and Fisher, 1975; Krogdahl, 1985; Sell et al., 1986). The inability to utilize fats has been attributed mainly to low bile salt concentrations in the intestine, rather than to deficiencies in lipase secretion or activation (Maisonnier et al., 2003; Maiorka et al., 2004). Limited levels of bile salt seem to be the first limiting step in fat digestion. Moreover, not only the synthesis but also the recirculation of bile is poor in newly hatched chickens (Krogdahl, 1985). According to Friedman and Nylund (1980), the absorption of long-chain saturated fatty acids is also limited by their incorporation rate into micelles. Saturated fatty acids have more difficulty to be solubilized into the micelles because of their non-polarity, which makes them rely on the presence of adequate amounts of bile salts or other emulsifying agents (Polin, 1980; Dänicke, 2001).

No significant differences in FI were found between treatments during the first 28 days of the rearing period. Group T4 birds, fed diets with reduced ME content supplemented with emulsifier, consumed equal levels of feed as turkeys from the high ME groups. The findings suggest that emulsifier improved nutrient digestibility, resulting in the fulfillment of the caloric requirements of birds and thus not leading to excess intake (Mathlouthi et al., 2002). Reduced dietary energy content usually leads to increased FI, and compromises growth performance, whereas, in our experiment, the BW and BWG of group T4 turkeys and control group birds were comparable after 112 days. According to Wang et al. (2016), the inclusion of emulsifier in lowenergy diets can increase the BWG of broiler chickens to the level determined in birds fed high-energy diets. 
The emulsifier had a significant positive effect on FCR in the high ME diets. Despite the fact that feed efficiency was lower in the starter phase in turkeys fed diets with reduced ME content and dietary emulsifier supplementation, in comparison with the high ME treatments, the overall FCR of group T4 birds was similar to the control group. Our results corroborate with several studies on emulsifiers in broiler chickens. Guerreiro Neto et al. (2011) reported that feed efficiency was higher in 14-day-old broilers fed diets supplemented with soybean oil and emulsifier, which could result from the fatty acid composition of this fat source and its effect on fat digestion and absorption. According to Ketels and DeGroote (1989), the utilization of dietary fat by broilers increases when the ratio between unsaturated and saturated fatty acids increases from 0 to 2.5 . The above differences in research findings could be due to differences in the potential and emulsifying properties of the applied emulsifiers. In a study of Zhang et al. (2011) the use of lysophosphatidylcholine tended to reduce FCR in the starter period. Similarly, broiler chicks fed diets supplemented with sodium stearoyl-2-lactate as emulsifier improved feed conversion ratio throughout the 35-day feeding period (Wang et al., 2016). Kaczmarek et al. (2015) concluded that birds fed diets supplemented with glyceryl polyethylene glycol ricinoleate were characterized by lower FCR during the whole trial.

According to Roy et al. (2010) and Zhang et al. (2011), the improvement in growth performance of broiler chickens receiving dietary emulsifier results at least partially from increased fat digestibility. In the above experiment, emulsifier significantly improved the digestibility of fat compared to the control diet without emulsifier, irrespective of its inclusion level. Turkeys fed diets with reduced ME content, supplemented with emulsifier, were characterized by identical fat digestibility as control group birds (T1). Our results are consistent with the findings of Maisonnier et al. (2003), Maertens et al. (2013), Kaczmarek et al. (2015), Parsaie et al. (2007), Cho et al. (2012) and Abbas et al. (2016), who reported a beneficial influence of emulsifiers on fat digestibility in broiler chickens. According to Cho et al. (2012), the above results could be attributed to the action of fat emulsifier as an emulsifying agent for dietary fat and a stabilizer for other feed ingredients. A better formation of emulsion droplets in the gut leads to a higher degree of lipolysis of triglycerides. In combination with an improved micelle formation, absorption of fat can be enhanced. The dietary addition of an emulsifier not only favors fat digestibility but also digestion of other nutrients is found to be increased because dietary lipids could cover other nutrients lowering their digestion (Zhang et al., 2011). Guerreiro Neto et al. (2011) argued that the emulsifier increased the availability of smaller fat particles, thereby favoring the action of lipase. These researchers argued that increasing the demand for pancreatic lipase actually induced the enzyme secretion, improving ether extract digestibility.

As already mentioned, due to the absence of studies investigating the effect of nutritional emulsifiers on turkey performance, we had to compare our findings with the results of experiments performed on broiler chickens. According to Mossab et al. (2000), who compared the utilization of vegetable and animal fats in young turkeys and chickens, one-week-old turkeys used fats, in particular saturated fats, more efficiently than chickens. This could suggest that turkeys may have higher bile salt secretion and lipase activity from 1 week of age. However, the authors also found that 
fluctuations in secretion of bile salts and lipase activity may influence saturated fatty acid digestibility in turkeys. Therefore, further research is needed to expand existing knowledge about fat utilization and the use of emulsifiers in diets for young turkeys.

The results of the present study indicate that the use of emulsifier positively affected the growth performance of turkeys. Regardless of its dietary inclusion level, the emulsifier positively influenced the BWG and, consequently, final BW of birds, and contributed to a significant increase in fat digestibility. Higher feed efficiency was also noted when the emulsifier was added to turkey diets at $500 \mathrm{~g} /$ ton in the first 8 weeks and at $250 \mathrm{~g} /$ ton in the last 8 weeks. The growth performance parameters of turkeys fed diets with reduced ME content (-3\%), supplemented with the emulsifier, were comparable with those noted in control group birds.

\section{Acknowledgements}

The authors wish to acknowledge Nukamel (Weert, The Netherlands) for providing Volamel Extra emulsifier and financial support for this project.

\section{References}

A bbas M.T., Arif M., S a e d M., R ey ad-ul-ferdous M., Has s a n M.A., Arain M.A., R e hman A. (2016). Emulsifier effect on fat utilization in broiler chicken. Asian J. Anim. Vet. Adv., 11: 158-167.

A bd E 1 R a u of M.A. (2007). Use of emulsifiers in high fat level diets of broilers; theses of doctor of philosophy in agricultural sciences (animal production and poultry nutrition). 2007, pp. 235.

Cho J.H., Z h a o P.Y., K i m I.H. (2012). Effects of emulsifier and multi-enzyme in different energy density diet on growth performance, blood profiles and relative organ weight in broiler chickens. J. Agric. Sci., 4: 161-168.

D ä n i c k e S. (2001). Interaction between cereal identity and fat quality and content in response to feed enzymes in broilers. In: Enzymes in Farm Animal Nutrition, Bedford M.R., Partridge G.G. (eds). London, UK, pp. 199-236.

D i e r i c k N.A., D e c u y p e r e J.A. (2004). Influence of lipase and/or emulsifier addition on the ileal and faecal nutrient digestibility in growing pigs fed diets containing $4 \%$ animal fat. J. Sci. Food Agr., 84: 1443-1450.

Fri e d m a n H.I., N y l u n d B. (1980) Intestinal fat digestion, absorption, and transport. A review. Am. J. Clin. Nutr., 33: 1108-1139.

Guerreiro Neto A.C., Pezzato A.C., Sartori J.R., Mori C., Cruz V.C., F a s c in a V.B., P in he iro D.F., Ma de ir a L.A., G on c a lve z J.C. (2011). Emulsifier in broiler diets containing different fat sources. Braz. J. Poult. Sci., 13: 119-125.

Hill F.W., Anderson D.L., Renner R., Carew Jr. L.B. (1960). Studies on the metabolizable energy of grain and grain products for chickens. Poultry Sci., 39: 573-579.

Hybrid Turkeys (2016). Commercial management guide. Converter commercial females performance goals. http://www.hybridturkeys.com.

J o n e s D.B., H a n c o c k J.D., H a r m o n D.L., Wa 1 ke r C.E. (1992). Effects of exogenous emulsifiers and fat sources on nutrient digestibility, serum lipids and growth performance in weanling pigs. J. Anim. Sci., 70: 3473-3482.

K a c z marek S.A., B ochenek M., S a mue ls s on A.C., Rutkowski A. (2015). Effects of glyceryl polyethylene glycol ricinoleate on nutrient utilization and performance of broiler chickens. Arch. Anim. Nutr., 69: 285-296.

Ketels E., De Groote G. (1989). Effect of ratio of unsaturated to saturated fatty acids of the dietary lipid fraction on utilization and metabolizable energy of added fats in young chicks. Poultry Sci., 68: 1506-1512. 
K r og d a h 1 A. (1985). Digestion and absorption of lipids in poultry. J. Nutr., 115: 675-685.

K r o g d a h 1 A., S e 11 J.L. (1989). Influence of age on lipase, amylase and protease activities in pancreatic tissue and intestinal contents of young turkeys. Poultry Sci., 68: 1561-1568.

Lim a A.C.F., Pizauro J.M. Jr., Mac ari M., Malhe iros E.B. (2003). Efeito do uso de probiótico sobre o desempenho e atividate de enzimas digestivas de frangos de corte. R. Bras. Zootec., 32: 200-207.

Maertens L., Seghers L., Rovers M., Leleu S., Van der A a A. (2013). The effect of different emulsifiers on fat and energy digestibility in broilers. Proc. 19th Europ. Symp. Poult. Nut., Potsdam, Germany, 26-29.08.2013, pp: 1-4.

Mai orka A., da Silva A.V.F., S ant in E., Pizauro J.M. Jr., Macari M. (2004). Broiler breeder age and dietary energy level on performance and pancreas lipase and trypsin activities of 7-days old chicks. Int. J. Poult. Sci., 3: 234-237.

Ma is onnier S., G om e z J., B re e A., B erri C., B a e z a E., C arre B. (2003). Effect of microflora status, dietary bile salts and guar gum on lipid digestibility, intestinal bile salts and histomorphology in broiler chickens. Poultry Sci., 82: 805-814.

Mathlouthi N., Lalles J.P., Leclercq P., Juste C., Larbier M. (2002). Xylanase and $\beta$-glucanase supplementation improve conjugated bile acid fraction in intestinal contents and increase villus size of small intestine wall in broiler chickens fed a rye-based diet. J. Anim. Sci., 80: 2773-2779.

M e n g X., S l o m in sk i B.A., G u e n te r W. (2004). The effect of fat type, carbohydrase, and lipase addition on growth performance and nutrient utilization of young broilers fed wheat-based diets. Poultry Sci., 83: 1718-1727.

M os s a b A., H a 11 o u i s J. M., Le s s ir e M. (2000). Utilization of soybean oil and tallow in young turkeys compared with young chickens. Poultry Sci., 79: 1326-1331.

$\mathrm{N}$ a u m a n n K., B a s s 1 e r R. (2004). Methodenbuch Band III: Die chemische Untersuchung von Futtermitteln. Neumann-Neudamm, Melsungen, Germany.

N i r I., N it s a n Z., M a ha g u a M. (1993). Comparative growth and development of the digestive organs and some enzymes in broiler and egg type chicks after hatching. Brit. Poultry Sci., 34: 523-532.

Parsaie S., Shariatmadari F., Zamir i M.J., Khajeh K. (2007). Influence of wheat-based diets supplemented with xylanase, bile acid and antibiotics on performance, digestive tract measurements and gut morphology of broilers compared with a maize-based diet. Brit. Poultry Sci., 48: 594-600.

P o 1 i n D. (1980). Increased absorption of tallow with lecithin. Poultry Sci., 59: 1652.

R o y A., H a ld a r S., G h o s h T.P. (2008). Nutritional emulsifiers: An innovative approach to enhance productivity. Asian Poultry Mag., 8: 36-39.

R o y A., Hald ar S., Mondal S., Gho sh T.P. (2010). Effects of supplemental exogenous emulsifier on performance, nutrient metabolism and serum lipid profile in broiler chickens. Vet. Med. Int., Article ID 262604, 9 pages.

S e 11 J.L., K rog d h a 1 A., H a n y N. (1986). Influence of age on supplemental fats by young turkeys. Poultry Sci., 65: 546-554.

S k 1 a n D. (2001). Development of the digestive tract of poultry. World. Poultry Sci. J., 57: 415-428.

W a n g J.P., Z h a n g Z.F., Y a n L., K i m I.H. (2016). Effect of dietary supplementation of emulsifier and carbohydrase on the growth performance, serum cholesterol and breast meat fatty acids profile of broiler chickens. Anim. Sci. J., 87: 250-256.

Whit e he ad C.C., F is her C. (1975). The utilisation of various fats by turkeys of different ages. Brit. Poultry Sci., 16: 481-485.

$\mathrm{Z}$ a e farian F., R o m e ro L.F., R a vindran V. (2015). Influence of high dose of phytase and an emulsifier on performance, apparent metabolizable energy and nitrogen retention in broilers fed on diets containing soy oil or tallow. Brit. Poultry Sci., 56: 590-597.

Z hang B., Hait a o L., Z h a o D., Gu o Y., B arri A. (2011). Effect of fat type and lysophosphatidylcholine addition to broiler diets on performance, apparent digestibility of fatty acids, and apparent metabolizable energy content. Anim. Feed Sci. Technol., 163: 177-184. 